\title{
Analysis of genetic variability of respiratory syncytial virus groups $A$ and $B$ in Kuwait
}

\author{
Nada Madi $^{1}$ (D) Wassim Chehadeh ${ }^{1} \cdot$ Mohammed Asadzadeh $^{1} \cdot$ Mariam Al-Turab $^{1} \cdot$ Anfal Al-Adwani $^{1}$
}

Received: 23 February 2018 / Accepted: 7 May 2018 / Published online: 19 May 2018

(c) Springer-Verlag GmbH Austria, part of Springer Nature 2018

\begin{abstract}
Respiratory syncytial virus (RSV) is the most frequently identified viral agent in infants, children, and elderly people with acute respiratory tract infections (ARTIs). This study is the only one of its kind in Kuwait, and its purpose was to investigate the genetic variability of the G protein gene in RSV strains prevalent in Kuwait. Respiratory samples were collected from patients with ARTIs in various hospitals in Kuwait and subjected to reverse transcription PCR (RT-PCR) amplifying a fragment of the G gene of RSV. A total of 305 samples were collected between January and mid-December 2016, and 77 (25.2\%) were positive for RSV. Group A viruses were predominant over group B viruses; the RSV-A group was detected in $52(67.5 \%)$ of the positive samples, while the RSV-B group was detected in 25 (32.5\%) of the positive samples. Phylogenetic analysis showed that all RSV-A strains grouped into eight clusters of identical sequences of untyped strains. Twelve RSV-B strains, on the other hand, belonged to the RSV-B/BA10 genotype, while the rest were untyped. These data suggest that new and untyped strains of RSV-A group likely predominated in Kuwait and that the BA10 genotype of the RSV-B group became the dominant genotype in the 2016 season.
\end{abstract}

\section{Introduction}

Respiratory syncytial virus (RSV) is the major pathogen of lower respiratory tract infections (LRTIs), which can be severe in infants, young children, and the elderly [1]. RSV infection is associated with a high rate of morbidity and mortality in children aged $<5$ years with acute lower respiratory infections (ALRIs) in both industrialised and developing countries [2-4]. RSV also is an important virus in

Handling Editor: Bert K. Rima.

Nada Madi

madi@hsc.edu.kw

Wassim Chehadeh

wassim.chehadeh@ku.edu.kw

Mohammed Asadzadeh

mohammad.assadzadeh@ku.edu.kw

Mariam Al-Turab

maryam.alturab@ku.edu.kw

Anfal Al-Adwani

anfal.a@ku.edu.kw

1 Virology Unit, Microbiology Department, Faculty of Medicine, Kuwait University, P.O. Box 24923, Safat, 13110 Kuwait City, Kuwait adults, causing $25 \%$ of lethal respiratory infections in cold seasons, similar to the rate for seasonal influenza [5]. Globally, studies have shown an RSV-associated mortality rate of about 26.5 cases per 100,000 persons/year among adults aged $>65$ years [6].

RSV is a member of the genus Orthopneumovirus, family Pneumoviridae. It has a nonsegmented, negative-sense RNA genome of approximately 15,200 nucleotides encoding 11 structural and non-structural proteins [7]. Of these proteins, the $\mathrm{G}$ protein, a type of II attachment glycoprotein of about 300 amino acids in length, is the most variable and is responsible for the differences between RSV genotypes. The $\mathrm{G}$ protein has two hypervariable regions, and the $\mathrm{C}$-terminal region (the second hypervariable region) contains strain-specific epitopes [7-9]. According to the reactivity of RSV with monoclonal antibodies against $\mathrm{G}$ glycoprotein, the virus is divided into two major antigenic groups: group $\mathrm{A}$ and group $\mathrm{B}[10,11]$. The RSV-A group is further subdivided into 11 genotypes, GA1-GA7, SAA1, NA1-, NA2 and ON1 [12-14], and the RSV-B group is subdivided into 23 genotypes: GB1GB4, SAB1-SAB3, SAB4, URU1, URU2, BA1-BA12, and THB [12, 15-21]. This strain variation allows the virus to evade the host's immune responses, which contribute to the capability of the virus to cause frequent re-infections and epidemics and creates a challenge for vaccine development 
Table 1 RSV group A G protein gene GenBank Reference Sequences
Table 2 RSV group B G protein gene GenBank Reference Sequences

\begin{tabular}{llll}
\hline Strain & GenBank accession no. & Strain & GenBank accession no. \\
\hline A2 & M11486 & sal/173/99 & AY472094 \\
NY108 & AF2339171 & AL/9452-2 & AF233901 \\
DEL/2 W/04/A & DQ248923.1 & NY20 & AF233918 \\
LLC235-267 & AY114149.1 & SA99V1239 & AF348808 \\
MO16 & AF33913.1 & WUE/16397/12 & JX912364 \\
TX68481 & AF233920.1 & MO02 & AF233910 \\
NY/CH09 & AF065254.1 & Cam2008-7262 & JN119952.1 \\
DEL/138/021A & DQ248894.1 & & \\
\hline
\end{tabular}

\begin{tabular}{llll}
\hline Strain & GenBank accession no. & Strain & GenBank accession no. \\
\hline WV10010 & M73541.1 & NG-147-02 & AB603480 \\
CH93-9b & AF065251 & BE/210/03 & AY751111 \\
NY97 & AF233932 & NG-095-05 & HM459865 \\
BA/3018/98 & AY672691 & NG-046-06 & AB603478 \\
Ken/2/03 & AY660684 & CU2011/205 & KC342347 \\
SA99V800 & AF348821 & BJ/20240 & KC297426 \\
Mon/7/99 & AY488800.1 & RSV/PUNE/ & KF246586 \\
Cam2009-2145 & JN119987 & NIV0931702/09/B & \\
Mon/7/01 & AY488804 & CU2011/81 & KC342343 \\
Mon/6/01 & IY488803 & SA98V602 & AF348824.1 \\
BA/770/02 & DQ227373 & SA0025 & AF233933.1 \\
NG-010-09 & HM459857 & SAQ98V192 & AF348825.1 \\
MAD/3743/02-03 & GQ150691 & AL19734-4 & AF348811.1 \\
BA/524/04 & DQ227396 & & AF233924.1 \\
\hline
\end{tabular}

[22]. Therefore, it is of great importance to identify the genotypes circulating in the population.

In Kuwait, information regarding the molecular epidemiology of RSV is lacking. The present study is the first one to investigate the genetic diversity and patterns of circulating genotypes of groups RSV-A and RSV-B collected from hospitalised patients with RTIs in comparison with other RSV genotypes circulating worldwide. This information will be beneficial for RSV vaccine development and implementation.

\section{Materials and methods}

\section{Study population and sample collection}

Retrospectively, we analysed patients admitted to different hospitals in Kuwait between January and mid-December 2016 with clinical symptoms of acute upper or lower RTI. Different respiratory samples were collected in the hospital from the patients, including nasopharyngeal aspirates/ washes, tracheal aspirates, and throat swabs. The collected samples were first screened for respiratory viruses, including RSV, using multiplex real-time PCR at the Virology Unit, Faculty of Medicine, Kuwait University. RSV-positive samples were stored frozen at $-70{ }^{\circ} \mathrm{C}$ for further molecular analysis by specific RSV PCR and phylogenetic analysis after nucleic acid sequencing. Detailed clinical data of the patients could not be obtained from their medical records.

\section{Nucleic acid extraction and diagnosis of RSV infection}

Viral RNA was extracted from clinical samples using a Roche ®MagNA Pure LC System (Roche Diagnostics, Indianapolis, IN, USA) according to the manufacturer's instructions with the addition of RNase inhibitor (Applied Biosystems, USA) after extraction. Extracted RNA from all samples was tested for RSV and other respiratory viruses using a multiplex real-time PCR assay. This assay can detect influenza A virus, influenza A (H1N1) swl virus, influenza $B$ virus, human rhinovirus (HRV), human coronavirus NL63 (HCoV-NL63), HCoV-229E, HCoV-OC43, HCoVHKU1, parainfluenza virus (PIV) types $1,2,3$, and 4 , human 
metapneumovirus (HMPV) A/B, bocavirus, respiratory syncytial virus (RSV) A/B, adenovirus (AdV), enterovirus, parechovirus, mycoplasma pneumonia, and an internal control, using a Fast Track Kit (Fast Track Diagnostics, Luxembourg). This PCR assay is a routine diagnostic test for the detection of respiratory viruses performed at the Virology Unit, Faculty of Medicine, Kuwait University.

\section{RT-PCR for the G protein gene of RSV}

A One-Step RT-PCR Kit (QIAGEN, GmbH, Hilden, Germany) was used to synthesise cDNA from the extracted RNA according to the manufacturer's instructions. The second hypervariable region of the G protein gene of RSV was amplified using external and semi-nested PCR. External PCR was performed using the forward primer ABG490 and the reverse primer F164. Semi-nested PCR was performed using the forward primer AG655 for group A and forward primer BG517 for group B along with reverse primer F164 as described previously [23]. PCR products of 450/585 and $645 \mathrm{bp}$ for group A/B and BA viruses, respectively, were analysed by $1 \%$ agarose gel electrophoresis.

\section{DNA sequencing}

The PCR products were purified using a QIAquick Gel Extraction Kit (QIAGEN) according to the manufacturer's instructions. Subsequently, the purified products were sequenced in the forward and the reverse directions using the forward primer AG655 for group A and BG517 for group $\mathrm{B}$, together with the reverse primer F164. Sequencing was performed using an ABI 3500/3500xL Genetic Analyzer (PE Applied Biosystems Inc., Foster City, CA, USA) with an ABI PRISM BigDye Terminator Cycle Sequencing Ready Reaction Kit (PE Applied Biosystems Inc., USA).

\section{Phylogenetic analysis}

The obtained nucleic acid sequences of the second hypervariable region of the G protein gene of RSV were edited manually and aligned with the available RSV sequences from the GenBank database (https://www.ncbi.nlm.nih.gov/) using the Clustal W method in MEGA software version 7 [24]. Phylogenetic trees were constructed using the neighbourjoining method, and bootstrap values with 1,000 replicates were calculated in MEGA software version 7. Pairwise distances between and within the genotypes of groups RSV-A and RSV-B at the nucleotide level were calculated using the Tamura-Nei Model. Reference strains representing each known genotype of RSV group A and group B were retrieved from GenBank and included in the trees. Fifteen published reference sequences of RSV group A and 27 reference sequences of RSV group B were used for comparison to the sequences obtained in this study. Online Resources 1 and 2 contain the GenBank accession numbers of RSV group A and RSV group B reference sequences used in the current study.

\section{Results}

\section{Detection of RSV}

Between January and mid-December 2016, a total of 305 respiratory samples from hospitalised infants, children and adults were analysed for respiratory viruses by multiplex real-time PCR, resulting in 77 (25.2\%) RSV-positive samples. Among the RSV-positive patients, 44 were females, and 33 were males, and their age ranged from five days to 79 years (median, two months). All RSV-positive samples were sequenced and further analysed to determine their genotypes. Of the viruses identified in the RSV-positive patients, $52(67.5 \%)$ were subgrouped as RSV-A and $25(32.5 \%)$ as RSV-B. Coinfections with RSV and other respiratory viruses were detected; RSV and rhinovirus were detected in $15(19.5 \%)$ patients; RSV, enterovirus and parainfluenza virus type 4 were detected in one (1.3\%) patient; and RSV and parainfluenza virus type 3 were detected in one (1.3\%) patient. The occurrence of RSV infection in the various age group, as shown in Figure 1, was as follows: $<12$ months, 51 (66\%); $1-5$ years, $13(17 \%)$; $6-13$ years, $2(3 \%)$; $14-28$ years, $1(1 \%)$; $28-60$ years, $2(3 \%)$; $>60$ years, $8(10 \%)$. The seasonal distribution of RSV-A and RSV-B in Kuwait is shown in Figure 2, with the peak of positivity being detected in January 2016 and the lowest positivity detected in February 2016.

\section{Phylogenetic analysis}

The sequences from 46 RSV group A and 22 group B Kuwaiti strains collected from the patients were included in a phylogenetic analysis, which revealed that the 46 RSV-A strains were untyped and did not belong to any of the known group A genotypes (Fig. 3A). Among these untyped Kuwaiti strains, 18 (39\%) were found to form eight clusters with identical sequences, with two to three sequences per cluster, while the remaining 28 (61\%) strains were sporadic single strains (Fig. 3A). The divergence between prototype strain A2 and the Kuwaiti strains ranged from 6\% to $22 \%$ at the nucleotide level, while differences of up to $19 \%$ were observed among all group A Kuwaiti strains. Moreover, strains in clusters 5 and 6 were genetically closer to the ON1 reference strain than strains in other clusters; the differences in the nucleotide sequence between strains in clusters 5 and 6 and ON1 ranged from $0.5 \%$ to $3 \%$, while the differences in the nucleotide sequences between strains from other 

positive patients
Fig. 1 Age distribution of RSV-

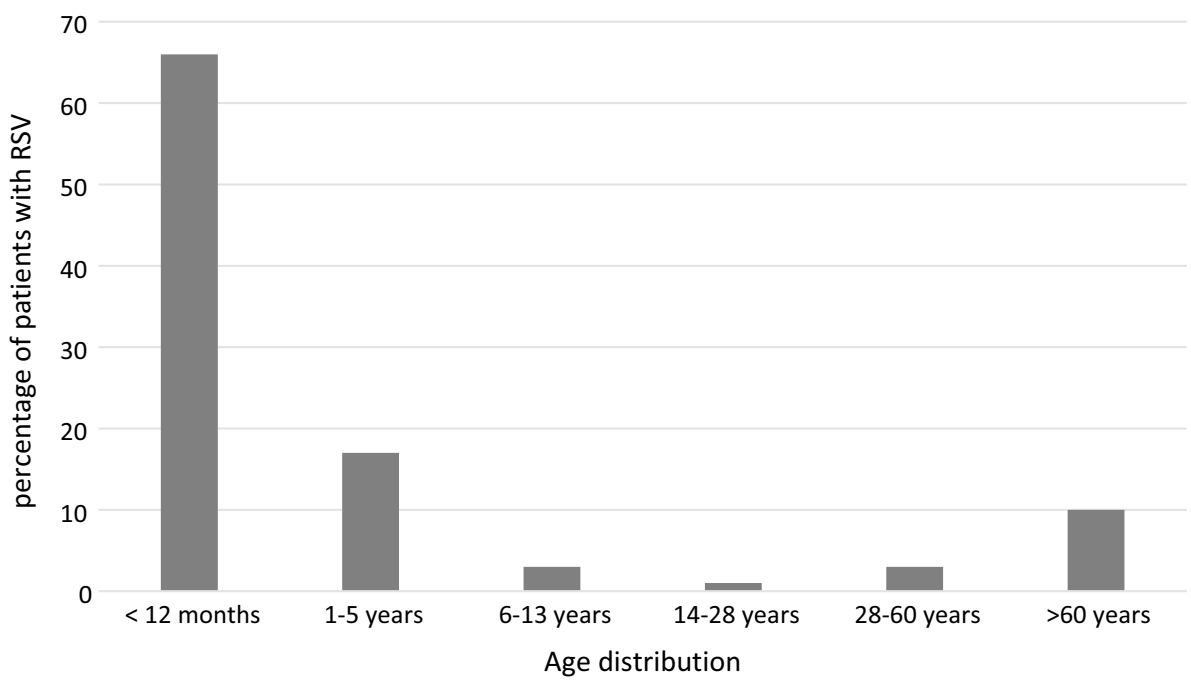

Fig. 2 Seasonal trends of subgroups RSV-A and RSV-B in patients with acute RTI in Kuwait from January to midDecember 2016

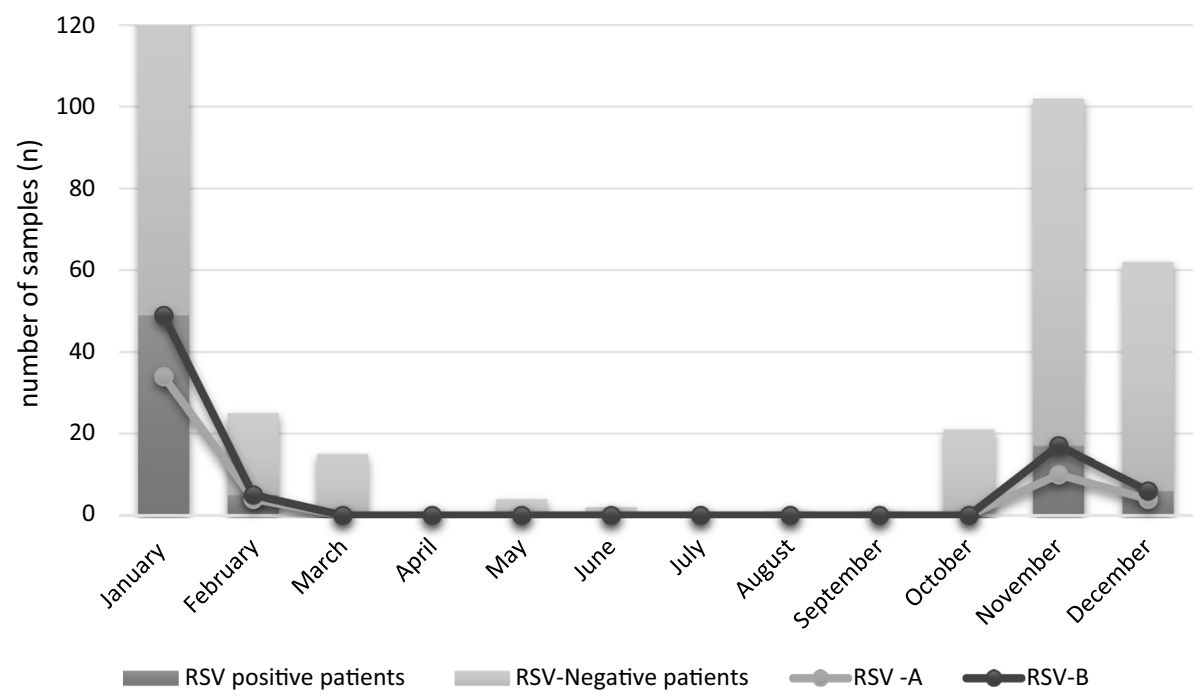

clusters and ON1 ranged from $0.5 \%$ to $16 \%$. Furthermore, the KW-827 and KW-1411 strains were genetically closer to the NA1 reference strain than other Kuwaiti strains. The nucleotide sequence difference between the NA1 reference strain and the KW-827 and KW-1411 strains was 3\% and $2 \%$, respectively. However, the differences in the nucleotide sequences between the NA1 reference strain and the rest of Kuwaiti strains ranged from $16 \%$ to $19 \%$.

The 22 RSV group B Kuwaiti strains clustered into four groups. Twelve (55\%) strains clustered with the BA10 genotype with bootstrap values of $65 \%$ to $85 \%$, and the divergence in the nucleotide sequences ranged from $0 \%$ to $4 \%$ between the Kuwaiti strains and BA10 references strains. The remaining 10 (45\%) Kuwaiti strains were clustered into three groups of untyped strains that do not belong to any of the known group B genotypes (Fig. 3B). Among these clusters, cluster 2 contained three identical sequences and one divergent strain with nucleotide sequence differences ranging from $0.4 \%$ to $1 \%$. Moreover, there was $3.5 \%$ to $7 \%$ divergence at the nucleotide level between the Kuwaiti strains and the prototype BA strain, while up to $7 \%$ differences in the nucleotide sequences were observed among all group B Kuwaiti strains.

\section{Discussion}

RSV is the most common viral pathogen causing acute lower respiratory tract infections in infants, children and older people. The present study is the first to investigate the frequency and genetic variability of RSV group A and group B in patients with ARTI in Kuwait. A total of 305 samples from ARTI patients, including infants, children and adults, were collected, and $77(25.2 \%)$ of the patients 
Fig. 3 Phylogenetic tree for RSV-A (A) and RSV-B (B) nucleotide sequences from the second variable region of the $G$ protein gene, constructed using the neighbor-joining method in MEGA version 7. Solid triangles indicate the sequences of the reference strains. Details for the reference GenBank sequences used for phylogenetic analysis are given in Table 1 and Table 2 for RSV-A and RSV-B strains, respectively. The scale bar indicates the proportion of nucleotide substitutions, and the numbers at the branches are bootstrap values determined for 1,000 repetitions. Bootstrap values greater than 50\% are shown at the branches. The evolutionary distances were computed using the Tamura-Nei method and are in units of base substitutions per site

were found to be positive for RSV by multiplex real-time PCR. Our results, which demonstrated the predominance of the RSV-A group over the RSV-B group in the clinical samples, are in agreement with the findings of the majority of the studies on the epidemiology of RSV genotypes $[23,25-30]$. We found that most of the patients had RSV single infections, while 17 (22\%) had mixed infections of RSV and other respiratory viruses. Furthermore, we found that coinfections with RSV and rhinovirus were the most commonly detected mixed infections among the patients $-\mathrm{a}$ finding consistent with those of previous studies [31-34]. These coinfections may influence the severity of respiratory disease in patients with RSV infection. Calvo et al. showed that coinfection with RSV and other respiratory viruses did not result in greater severity of disease, but did result in mixed clinical features [31]. Goka et al. on the other hand, demonstrated an increased risk of admission to the intensive care unit (ICU) and death as a result of coinfection with RSV and other respiratory viruses [35]. In this study, however, we were unable to investigate the association between RSV groups or coinfections on the severity of the RSV respiratory diseases due to the lack of clinical data for the patients.

Since little is known about the distribution of RSV infection in different age groups, in this study we analysed the age distribution of the patients with RSV infections. Our results showed that infants less than one year of age represented that largest proportion of patients with RSV infections (66\%), followed by children between one and five years old (17\%). The prevalence decreased to $3 \%$ in children between six and 13 years old and further decreased to only $1 \%$ in children and adults between 14 to 28 years old. Many other studies have also demonstrated a high incidence of RSV infection and disease among infants less than one year old [36, 37]. a recent epidemiological meta-analysis study implicated RSV as one of the most significant pathogens of early childhood and placed it as the second-most-likely single pathogen to cause death in children less than one year of age [38-40]. Although there is evidence that maternal antibodies in infants are likely to be important in protection against RSV disease, severe disease was noted in children under six months of age, indicating that maternal RSV-specific antibodies are protective during the first 6-7 months, but

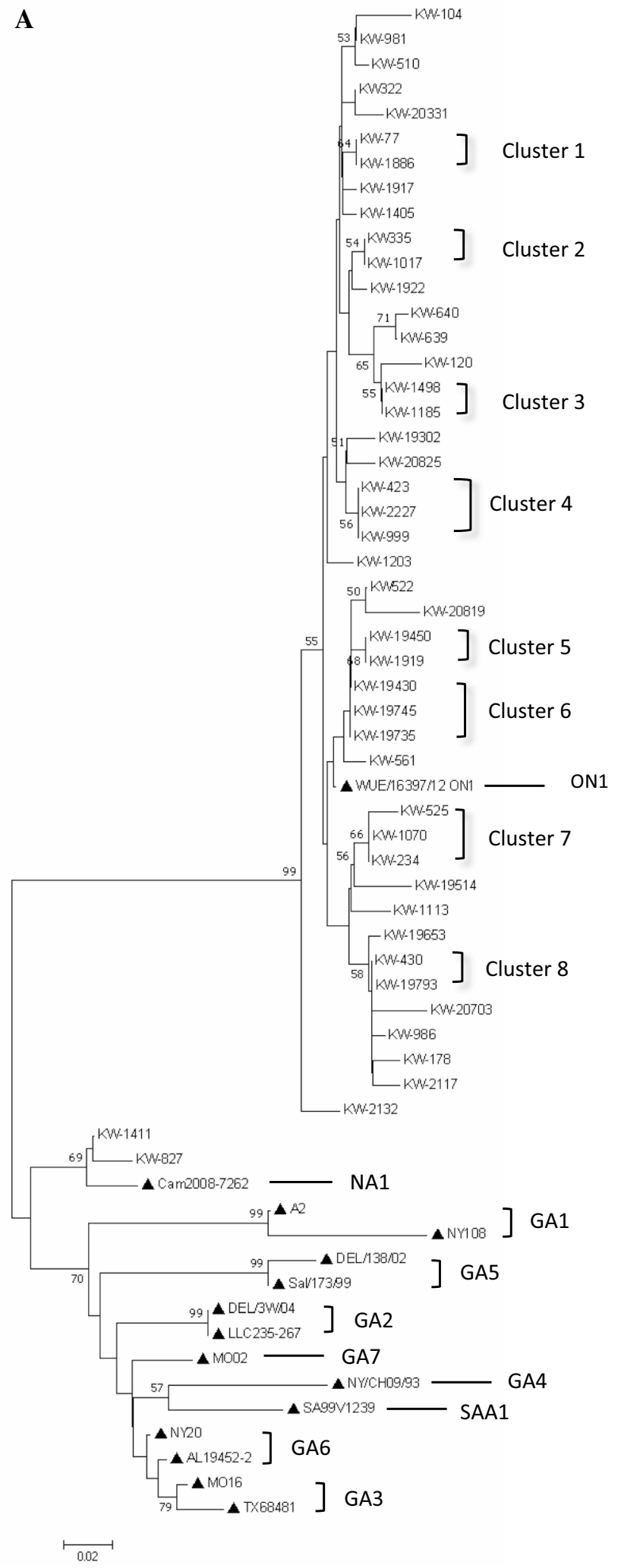

this protection may then wane [41]. There are other risk factors known to predispose infants to RSV-associated disease, including physical and immunological immaturity, which 


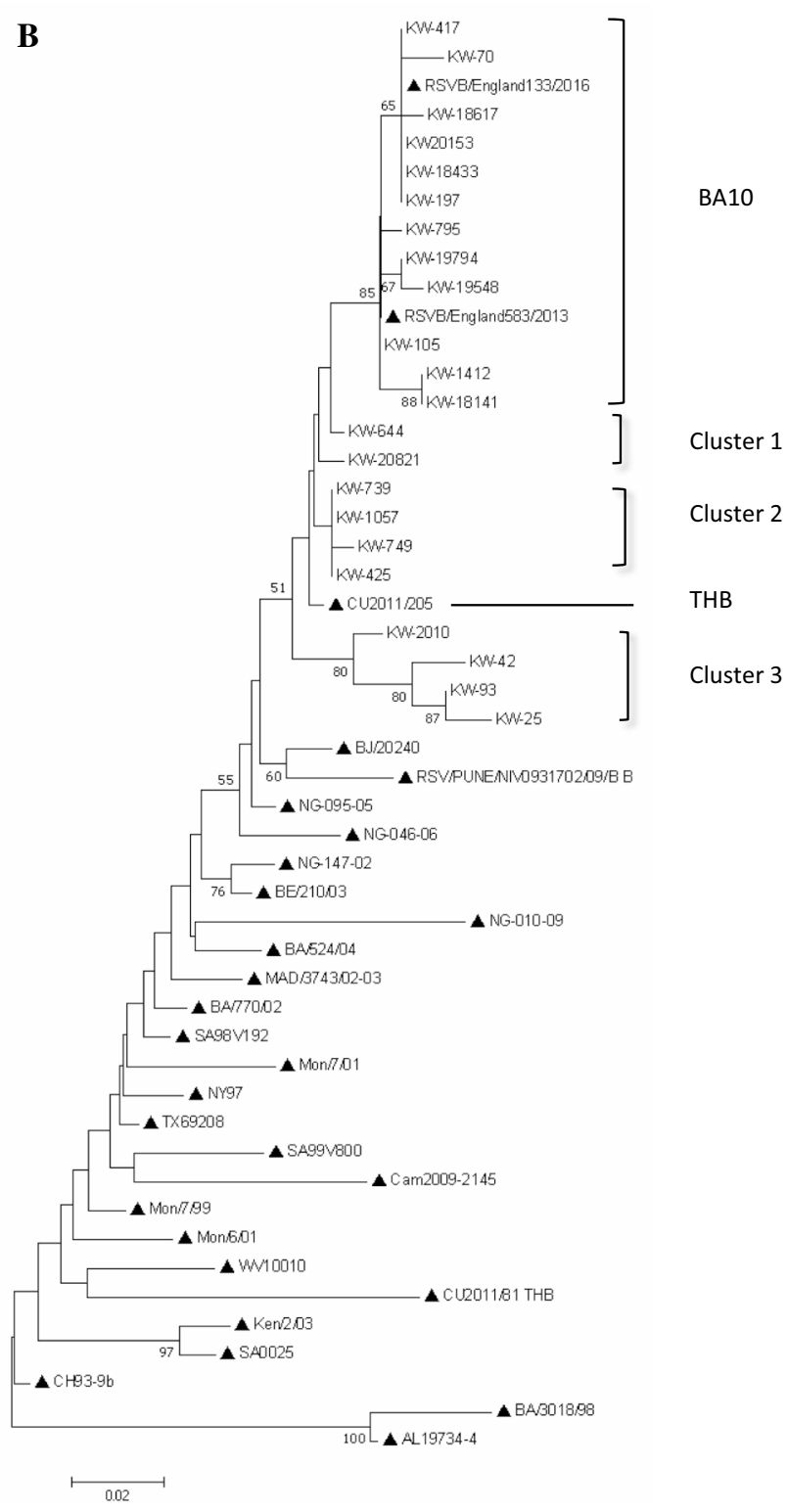

Fig. 3 (continued)

causes infants younger than three months to be the most susceptible to severe disease. Also, the size of the airway is specifically problematic in neonates and young infants because obstruction from sloughed epithelium, fibrin, inflammatory debris, and mucus is a significant factor in disease pathogenesis. In fact, the period after birth is critical in the development of the lung architecture and cellular functions, including the development of immunological effector mechanisms to deal with commensal and pathogenic microorganisms [42-44]. It has been shown that an immune system that is weak in the early years will mature sooner when children are re-infected for the second or third time [45]. Our results showed that the prevalence of RSV infection reached $10 \%$ in patients $>60$ years old, whose immune response is weakened by age. Similar observations have been made in other studies [46-50]. Researchers have found that infants infected with RSV develop maternal antibodies that recognise both the F and $\mathrm{G}$ proteins. However, in older infants, there is a dramatic increase in antibodies recognizing the $\mathrm{G}$ protein, while infection provokes only a modest increase in antibodies against the $\mathrm{F}$ protein. It was also shown that antibodies against the $\mathrm{F}$ protein continue to increase with age, whereas those against the $\mathrm{G}$ protein decrease [51].

RSV infection is characterised by a seasonality that may be associated with region and climate. Many studies have shown that RSV infection in non-tropical countries occurs almost year-round and peaks mainly during winter $[47$, 52-54], which is different from what has been reported in tropical countries [55]. In our study, however, RSV infection was detected in patients in autumn to spring (November to February) but peaked in winter (January), a result that is in coordinance with studies conducted in non-tropical countries. The cold and sometimes dry conditions of the winter season in Kuwait favour survival of RSV in the environment and encourage people to crowd together indoors, which may increase the chance of parents and older siblings acquiring RSV infection and passing it on to infants in the home. Also, the cold and relative humidity conditions in winter might delay the drying of large respiratory droplets, which could favour RSV survival and transmission, since RSV is predominantly transmitted through large droplets [56].

Interestingly, phylogenetic analysis showed that all RSV-A strains collected from the patients in this study were untyped strains that did not belong to any of the known group A genotypes in the Genbank database. Furthermore, the data showed that these Kuwaiti strains formed different clusters of identical sequences. These data indicate that there is heterogeneity among the Kuwaiti strains, which differ from the known RSV-A genotypes. One can speculate that these are new strains or that they originate through recombination of other known strains. Whole-genome sequencing of these isolates is necessary to address this question. Although they were untyped, RSV-A Kuwaiti strains in cluster 5 (Fig. 3A) were more closely related to the new RSV-A/ON1 genotype than the rest of the Kuwaiti strains according to the percentage of differences in the nucleotide sequences. RSV-A/ON1 is novel genotype that was first described by Eshaghi et al. in Ontario, Canada [57], and this strain later emerged and became the dominant genotype in different countries, including northern Italy, Germany, Thailand, Turkey, and Saudi Arabia [16, 19, 30, 47, 54, 58-61]. A further significant result is that the two Kuwaiti strains (KW-1411 and KW-827) were more closely related to the RSV-A/NA1 strain than other Kuwaiti strains based on pairwise nucleotide distances. The RSV-A/NA1 genotype and the NA2 genotype are new variants of A2 genotype that caused large epidemics in Japan during the 2005-2006 
and 2006-2007 seasons because of the lack of immunity in the children [62]. Also, the AN1 genotype was a dominated genotype in India among children $<6$ years old during the period 2009-2012 [28] and in Italy among children $<3$ years old during 2006-2012 [63]. Moreover, between October and December 2014, NA1 and ON1 genotypes of group A RSV dominated in Riyadh, Saudi Arabia, among children less than five years of age with ARI symptoms [30].

In this study, the RSV-B/BA10 genotype was the predominant genotype among Kuwaiti RSV-B strains, while the rest of the Kuwaiti RSV-B strains formed three clusters of untyped strains. RSV-B/BA genotypes emerged in the late 1990s and then spread globally and became the predominant genotypes [64]. Many studies have divided members in the BA clade into 13 different genotypes. However, other studies disagree on the total number of genotypes because they use different reference sequences for the genotypes. Therefore, there is overlap between genotypes, as evidenced by a partial CDS tree [65]. In our study, in the phylogenetic tree, we used different BA reference sequences that represented BA1 to BA10, and it was easily to identify the BA10 strains in particular. Previous studies have also demonstrated the predominance of RSV-B/BA genotypes, which is in line with our findings [17, 19, 25, 66, 67]. Interestingly, some reports have shown that genotype BA had replaced other prevailing genotypes in certain places, such as Argentina and India [21, 23]. It has been speculated that antigenic changes in the $G$ protein and the evasion of host immune responses had led to the selective advantage of genotype BA viruses over other RSV-B genotypes [21].

\section{Conclusion}

In summary, the findings of this study provide vital information regarding the frequency of RSV infection among patients of different age with ARTI in Kuwait. Sequence analysis of the circulating strains demonstrated the predominance of the RSV-A group over the RSV-B group in these patients. Additionally, the circulating RSV-A strains were untyped strains, indicating heterogenicity among group A RSV strains. On the other hand, most of the strains of the RSV-B group belonged to the BA10 genotype, showing the predominance of this genotype among patients with ARTI in Kuwait. We are firmly recommending whole-genome sequencing of the untyped Kuwaiti strains for full strain characterisation, which will be accomplished in the next project. Further surveillance and sequencing of RSV strains are required to determine if these untyped Kuwaiti strains are still circulating in this region and if the dominance of certain RSV genotypes over others is sustained over time or fluctuates from year to year. The knowledge obtained in the study may be beneficial for the development of a future vaccine against RSV.

Acknowledgements This work was supported by an initiation Grant from the Research Sector, Kuwait University, Kuwait (Grant no: ZM04/16).

\section{Compliance with ethical standards}

Conflict of interest The authors declare that they have no competing interests.

\section{References}

1. Lee W-J, Kim Y, Kim D-W et al (2012) Complete genome sequence of human respiratory syncytial virus genotype A with a 72-nucleotide duplication in the attachment protein $\mathrm{G}$ gene. $\mathrm{J}$ Virol 86:13810-13811. https://doi.org/10.1128/JVI.02571-12

2. Nair H, Nokes DJ, Gessner BD et al (2010) Global burden of acute lower respiratory infections due to respiratory syncytial virus in young children: a systematic review and meta-analysis. Lancet (London, England) 375:1545-1555. https://doi.org/10.1016/s0140 -6736(10)60206-1

3. Hon KL, Leung TF, Cheng WY et al (2012) Respiratory syncytial virus morbidity, premorbid factors, seasonality, and implications for prophylaxis. J Crit Care 27:464-468. https://doi.org/10.1016/j. jerc.2011.12.001

4. Lukšić I, Kearns PK, Scott F et al (2013) Viral etiology of hospitalized acute lower respiratory infections in children under 5 years of age - a systematic review and meta-analysis. Croat Med J 54:122-134. https://doi.org/10.3325/cmj.2013.54.122

5. Faghihloo E, Rezaie F, Salimi V et al (2011) Molecular epidemiology of human respiratory syncytial virus in Iran. Acta Virol. 55:81-83

6. Thompson WW, Shay DK, Weintraub E et al (2003) Mortality associated with influenza and respiratory syncytial virus in the United States. JAMA 289:179-186. https://doi.org/10.1001/ jama.289.2.179

7. Cane PA (2001) Molecular epidemiology of respiratory syncytial virus. Rev Med Virol 11:103-116. https://doi.org/10.1002/ rmv.305

8. Cane PA, Pringle CR (1995) Evolution of subgroup A respiratory syncytial virus: evidence for progressive accumulation of amino acid changes in the attachment protein. J Virol 69:2918-2925

9. Cane PA (1997) Analysis of linear epitopes recognised by the primary human antibody response to a variable region of the attachment $(\mathrm{G})$ protein of respiratory syncytial virus. J Med Virol 51:297-304

10. Mufson MA, Orvell C, Rafnar B, Norrby E (1985) Two distinct subtypes of human respiratory syncytial virus. J Gen Virol 66(Pt 10):2111-2124. https://doi.org/10.1099/0022-1317-66-10-2111

11. Anderson LJ, Hierholzer JC, Tsou C et al (1985) Antigenic characterization of respiratory syncytial virus strains with monoclonal antibodies. J Infect Dis 151:626-633

12. Peret TC, Hall CB, Schnabel KC et al (1998) Circulation patterns of genetically distinct group A and B strains of human respiratory syncytial virus in a community. J Gen Virol 79(Pt 9):2221-2229. https://doi.org/10.1086/315508

13. Peret TC, Hall CB, Hammond GW et al (2000) Circulation patterns of group A and B human respiratory syncytial virus genotypes in 5 communities in North America. J Infect Dis 181:18911896. https://doi.org/10.1086/315508 
14. Venter M, Madhi SA, Tiemessen CT, Schoub BD (2001) Genetic diversity and molecular epidemiology of respiratory syncytial virus over four consecutive seasons in South Africa: Identification of new subgroup A and B genotypes. J Gen Virol 82:2117-2124. https://doi.org/10.1099/0022-1317-82-9-2117

15. Arnott A, Vong S, Mardy S et al (2011) A study of the genetic variability of human respiratory syncytial virus (HRSV) in Cambodia reveals the existence of a new HRSV group B genotype. J Clin Microbiol 49:3504-3513. https://doi.org/10.1128/JCM.01131-11

16. Auksornkitti V, Kamprasert N, Thongkomplew S et al (2014) Molecular characterization of human respiratory syncytial virus, 2010-2011: Identification of genotype ON1 and a new subgroup B genotype in Thailand. Arch Virol 159:499-507. https://doi. org/10.1007/s00705-013-1773-9

17. Baek YH, Choi EH, Song M-S et al (2012) Prevalence and genetic characterization of respiratory syncytial virus (RSV) in hospitalized children in Korea. Arch Virol 157:1039-1050. https://doi. org/10.1007/s00705-012-1267-1

18. Blanc A, Delfraro A, Frabasile S, Arbiza J (2005) Genotypes of respiratory syncytial virus group B identified in Uruguay. Arch Virol 150:603-609. https://doi.org/10.1007/s00705-004-0412-x

19. Dapat IC, Shobugawa Y, Sano Y et al (2010) New genotypes within respiratory syncytial virus group B genotype BA in Niigata, Japan. J Clin Microbiol 48:3423-3427. https://doi. org/10.1128/JCM.00646-10

20. Khor CS, Sam IC, Hooi PS, Chan YF (2013) Displacement of predominant respiratory syncytial virus genotypes in Malaysia between 1989 and 2011. Infect Genet Evol 14:357-360. https:// doi.org/10.1016/j.meegid.2012.12.017

21. Trento A, Viegas M, Galiano M et al (2006) Natural history of human respiratory syncytial virus inferred from phylogenetic analysis of the attachment $(\mathrm{G})$ glycoprotein with a 60-nucleotide duplication. J Virol 80:975-984. https://doi.org/10.1128/ JVI.80.2.975-984.2006

22. Hall CB, Walsh EE, Long CE, Schnabel KC (1991) Immunity to and frequency of reinfection with respiratory syncytial virus. J Infect Dis 163:693-698. https://doi.org/10.1093/infdis/163.4.693

23. Parveen S, Sullender WM, Fowler K et al (2006) Genetic variability in the $\mathrm{G}$ protein gene of group A and B respiratory syncytial viruses from India. J Clin Microbiol 44:3055-3064. https://doi. org/10.1128/JCM.00187-06

24. Kumar S, Stecher G, Tamura K (2016) MEGA7: molecular evolutionary genetics analysis version 7.0 for bigger datasets. Mol Biol Evol 33:1870-1874. https://doi.org/10.1093/molbev/msw054

25. Zhang ZY, Du LN, Chen X et al (2010) Genetic variability of respiratory syncytial viruses (RSV) Prevalent in southwestern china from 2006 to 2009: Emergence of subgroup B and A RSV as dominant strains. J Clin Microbiol 48:1201-1207. https://doi. org/10.1128/JCM.02258-09

26. Zhang $\mathrm{Y}, \mathrm{Xu} \mathrm{W}$, Shen $\mathrm{K}$ et al (2007) Genetic variability of group $\mathrm{A}$ and $\mathrm{B}$ human respiratory syncytial viruses isolated from 3 provinces in China. Arch Virol 152:1425-1434. https://doi. org/10.1007/s00705-007-0984-3

27. Coggins WB, Lefkowitz EJ, Sullender WM (1998) Genetic variability among group A and group B respiratory syncytial viruses in a children's hospital. J Clin Microbiol 36:3552-3557

28. Biswas D, Yadav K, Borkakoty B, Mahanta J (2013) Molecular characterization of human respiratory syncytial virus NA1 and GA5 genotypes detected in Assam in northeast India, 2009-2012. J Med Virol 85:1639-1644. https://doi.org/10.1002/jmv.23636

29. Amer HM, Alshaman MS, Farrag MA et al (2016) Epidemiology of 11 respiratory RNA viruses in a cohort of hospitalized children in Riyadh, Saudi Arabia. J Med Virol 88:1086-1091. https://doi. org/10.1002/jmv.24435

30. Ahmed A, Haider SH, Parveen S et al (2016) Co-circulation of $72 \mathrm{bp}$ duplication group A and $60 \mathrm{bp}$ duplication group
B respiratory syncytial virus (RSV) strains in Riyadh, Saudi Arabia during 2014. PLoS One. https://doi.org/10.1371/journ al.pone. 0166145

31. Calvo C, Garcia-Garcia ML, Pozo F et al (2015) Respiratory syncytial virus coinfections with rhinovirus and human bocavirus in hospitalized children. Med (United States) 94:e1788. https://doi.org/10.1097/MD.0000000000001788

32. Drews AL, Atmar RL, Glezen WP et al (1997) Dual respiratory virus infections. Clin Infect Dis 25:1421-1429

33. Costa LF, Queiróz DAO, Lopes da Silveira H et al (2014) Human rhinovirus and disease severity in children. Pediatrics 133:e312-e321. https://doi.org/10.1542/peds.2013-2216

34. Pinky L, Dobrovolny HM (2016) Coinfections of the respiratory tract: Viral competition for resources. PLoS One. https://doi. org/10.1371/journal.pone.0155589

35. Goka EA, Vallely PJ, Mutton KJ, Klapper PE (2015) Single, dual and multiple respiratory virus infections and risk of hospitalization and mortality. Epidemiol Infect 143:37-47. https:// doi.org/10.1017/S0950268814000302

36. Boyce TG, Mellen BG, Mitchel EF et al (2000) Rates of hospitalization for respiratory syncytial virus infection among children in medicaid. J Pediatr 137:865-870. https://doi. org/10.1067/mpd.2000.110531

37. Shay DK, Holman RC, Newman RD et al (1999) Bronchiolitisassociated hospitalizations among US children, 1980-1996. J Am Med Assoc 282:1440-1446. https://doi.org/10.1001/ jama.282.15.1440

38. Lozano R, Naghavi M, Foreman K et al (2013) Global and regional mortality from 235 causes of death for 20 age groups in 1990 and 2010: a systematic analysis for the Global Burden of Disease Study 2010. Lancet 380:2095-2128. https://doi. org/10.1016/S0140-6736(12)61728-0

39. Ruckwardt TJ, Morabito KM, Graham BS (2016) Determinants of early life immune responses to RSV infection. Curr Opin Virol 16:151-157

40. Fagbo SF, Garbati MA, Hasan R et al (2017) Acute viral respiratory infections among children in MERS-endemic Riyadh, Saudi Arabia, 2012-2013. J Med Virol 89:195-201. https://doi. org/10.1002/jmv. 24632

41. Ochola R, Sande C, Fegan G et al (2009) The level and duration of RSV-specific maternal IgG in infants in kilifi Kenya. PLoS One. https://doi.org/10.1371/journal.pone.0008088

42. Burri PH (2006) Structural aspects of postnatal lung development-alveolar formation and growth. In: Biology of the neonate. pp 313-322

43. Stocks J, Hislop A, Sonnappa S (2013) Early lung development: lifelong effect on respiratory health and disease. Lancet Respir Med 1:728-742

44. Dowling DJ, Levy O (2014) Ontogeny of early life immunity. Trends Immunol 35:299-310

45. Ruuskanen O, Ogra PL (1993) Respiratory syncytial virus. Curr Probl Pediatr 23:50-79. https://doi.org/10.1016/00459380(93)90003-U

46. Cui D, Feng L, Chen Y et al (2016) Clinical and epidemiologic characteristics of hospitalized patients with laboratoryconfirmed respiratory syncytial virus infection in eastern China between 2009 and 2013: a retrospective study. PLoS One. https ://doi.org/10.1371/journal.pone.0165437

47. Bayrakdar F, Kocabas CN, Altas AB et al (2018) Genetic variability human respiratory syncytial virus subgroups A and B in Turkey during six successive epidemic seasons, 2009-2015. J Med Virol 90:456-463. https://doi.org/10.1002/jmv.24983

48. Feng L, Li Z, Zhao S et al (2014) Viral etiologies of hospitalized acute lower respiratory infection patients in China, 2009-2013. PLoS One. https://doi.org/10.1371/journal.pone.0099419 
49. Fry AM, Chittaganpitch M, Baggett HC et al (2010) The burden of hospitalized lower respiratory tract infection due to respiratory syncytial virus in rural Thailand. PLoS One 5:e15098. https://doi. org/10.1371/journal.pone.0015098

50. Bigogo GM, Breiman RF, Feikin DR et al (2013) Epidemiology of respiratory syncytial virus infection in rural and urban Kenya. J Infect Dis 208(Suppl):S207-S216. https://doi.org/10.1093/infdi s/jit489

51. Fuentes S, Coyle EM, Beeler J et al (2016) Antigenic fingerprinting following primary RSV infection in young children identifies novel antigenic sites and reveals unlinked evolution of human antibody repertoires to fusion and attachment glycoproteins. PLoS Pathog. https://doi.org/10.1371/journal.ppat.1005554

52. Agrawal AS, Sarkar M, Ghosh S et al (2009) Prevalence of respiratory syncytial virus group B genotype BA-IV strains among children with acute respiratory tract infection in Kolkata, Eastern India. J Clin Virol 45:358-361. https://doi.org/10.1016/j. jcv.2009.05.013

53. Panayiotou C, Richter J, Koliou M et al (2014) Epidemiology of respiratory syncytial virus in children in Cyprus during three consecutive winter seasons (2010-2013): age distribution, seasonality and association between prevalent genotypes and disease severity. Epidemiol Infect 142:2406-2411. https://doi.org/10.1017/S0950 268814000028

54. Tabatabai J, Prifert C, Pfeil J et al (2014) Novel respiratory syncytial virus (RSV) genotype ON1 predominates in germany during winter season 2012-13. PLoS One. https://doi.org/10.1371/journ al.pone.0109191

55. Weber MW, Mulholland EK, Greenwood BM (1998) Respiratory syncytial virus infection in tropical and developing countries. Trop Med Int Health 3:268-280

56. Hall CB, Douglas RG (1981) Modes of transmission of respiratory syncytial virus. J Pediatr 99:100-103. https://doi.org/10.1016/ S0022-3476(81)80969-9

57. Eshaghi AR, Duvvuri VR, Lai R et al (2012) Genetic variability of human respiratory syncytial virus a strains circulating in Ontario: a novel genotype with a 72 nucleotide $\mathrm{G}$ gene duplication. PLoS One. https://doi.org/10.1371/journal.pone.0032807

58. Esposito S, Piralla A, Zampiero A et al (2015) Characteristics and their clinical relevance of respiratory syncytial virus types and genotypes circulating in Northern Italy in five consecutive winter seasons. PLoS One. https://doi.org/10.1371/journal.pone.01293 69

59. Pierangeli A, Trotta D, Scagnolari C et al (2014) Rapid spread of the novel respiratory syncytial virus a on1 genotype, central Italy, 2011 to 2013. Eurosurveillance. https://doi.org/10.2807/15607917.ES2014.19.26.20843

60. Balmaks R, Ribakova I, Gardovska D, Kazaks A (2014) Molecular epidemiology of human respiratory syncytial virus over three consecutive seasons in Latvia. J Med Virol 86:1971-1982. https ://doi.org/10.1002/jmv.23855

61. Choudhary ML, Anand SP, Wadhwa BS, Chadha MS (2013) Genetic variability of human respiratory syncytial virus in Pune, Western India. Infect Genet Evol 20:369-377. https://doi. org/10.1016/j.meegid.2013.09.025

62. Shobugawa Y, Saito R, Sano Y et al (2009) Emerging genotypes of human respiratory syncytial virus subgroup A among patients in Japan. J Clin Microbiol 47:2475-2482. https://doi.org/10.1128/ JCM.00115-09

63. Martinelli M, Frati ER, Zappa A et al (2014) Phylogeny and population dynamics of respiratory syncytial virus (Rsv) A and B. Virus Res 189:293-302. https://doi.org/10.1016/j.virus res.2014.06.006

64. Trento A, Galiano M, Videla C et al (2003) Major changes in the $\mathrm{G}$ protein of human respiratory syncytial virus isolates introduced by a duplication of 60 nucleotides. J Gen Virol 84:3115-3120. https://doi.org/10.1099/vir.0.19357-0

65. Bose ME, He J, Shrivastava S et al (2015) Sequencing and analysis of globally obtained human respiratory syncytial virus a and B genomes. PLoS One. https://doi.org/10.1371/journal.pone.01200 98

66. Ren L, Xiao Q, Zhou L et al (2015) Molecular characterization of human respiratory syncytial virus subtype B: a novel genotype of subtype B circulating in China. J Med Virol 87:1-9. https://doi. org/10.1002/jmv.23960

67. Kushibuchi I, Kobayashi M, Kusaka T et al (2013) Molecular evolution of attachment glycoprotein $(\mathrm{G})$ gene in human respiratory syncytial virus detected in Japan 2008-2011. Infect Genet Evol 18:168-173. https://doi.org/10.1016/j.meegid.2013.05.010 